\title{
zmir Seferihisar ilçesinde organik üretimi yapılan şevketi bostan (Scolymus hispanicus L.) bitkisinde görülen zararlı böcekler üzerine bir araştırma ${ }^{1}$
}

\author{
A research on the pests observed on organically produced blessed thistle plants \\ (Scolymus hispanicus L.) in Seferihisar ( zmir, Turkey) district
}

Bilge GÜLLÜDAĞ

Zeynep YOLDAŞ ${ }^{2 \star}$

\section{Summary}

This study aims to cultivate healthy and high quality crops by revealing the pests on Blessed Thistle (Scolymus hispanicus L.) and controlling those species through conducting appropriate pest management programs and decreasing crop losses.

In this study the pests on the blessed thistle plants were determined between August 2013 (sowing stage) and August 2014 (maturation of seed). The trials were conducted in the 6 predetermined fields. The pest counting was carried out from the upper foliar parts of the randomly selected 100 plants, as to represent each field, once a week for the first 3 months and once every two weeks during the following 3 months till to the harvest. Counting was progressed once a month for 10 plants until seeds obtained. During the counting and harvest, the dry and damaged parts of the Blessed Thistle plants were surveyed together with roots to determine contamination situations with the pests.

As a result of the study, 15 species belonging to Orthoptera, Hemiptera, Coleoptera and Diptera have been identified. Within these species Chromatomyia horticola (Goureau), Liriomyza sativae (Blanchard) (Diptera: Agromyzidae) and Brachycaudus helichrysi (Kaltenbach) (Hemiptera: Aphididae) have been evaluated as the most harmful species that need to be focused on in the further studies.

Key words: Seferihisar, Scolymus hispanicus L., pests, species detected

\section{Özet}

$\mathrm{Bu}$ çalışma ile sağlıklı ve kaliteli ürün yetiştirmek için şevketi bostan (Scolymus hispanicus L.) bitkisinde görülen zararlı türlerin ortaya çıkarılması, uygun zararlı yönetim programları ile mücadele edilmesi ve böylece ürün kayıplarının azaltılması hedeflenmiştir.

Bu çalışmada 2013 Ağustos ayında şevketi bostan tohumunun ekilmesinden, 2014 Ağustos ayında tohumların olgunlaştığı döneme kadar olan süreçte karşılaşılan zararlılar saptanmıştır. Çalışma önceden belirlenen altı tarlada yürütülmüştür. Zararlı sayımları hasada kadar her tarlayı temsil edecek şekilde rastgele seçilen, 100 bitkinin üst aksamında ilk 3 ay boyunca haftada bir, sonraki 3 ay boyunca ise iki haftada bir kez olacak şekilde gerçekleştirilmiştir. Sayımlar tohum elde edilinceye kadar 10 bitkide ayda bir defa gerçekleştirilmeye devam edilmiştir. Sayımlar sırasında, kuruma ve hasar görülen bitkiler ile hasat sırasında şevketi bostan bitkisinin toprakaltı kısımları incelenerek zararlı ile bulaşıklık durumu da belirlenmiştir.

Çalışma sonucunda, Orthoptera, Hemiptera, Coleoptera ve Diptera takımlarına ait 15 tür belirlenmiştir. Bunlar içerisinden Chromatomyia horticola (Goureau), Liriomyza sativae (Blanchard) (Diptera: Agromyzidae) ve Brachycaudus helichrysi (Kaltenbach) (Hemiptera: Aphididae) ileride üzerinde durulması gereken en zararlı türler olarak değerlendirilmiştir.

Anahtar sözcükler: Seferihisar, Scolymus hispanicus L., zararlılar, tespit edilen türler

\footnotetext{
${ }^{1}$ Bu çalışma birinci yazarın yüksek lisans tezinin özetidir

2 Ege Üniversitesi Ziraat Fakültesi, Bitki Koruma Bölümü, 35100 Bornova/ ZM R

* Sorumlu yazar (Corresponding author) e-mail: zeynep.yoldas@ege.edu.tr

Alınış (Received): 29.04.2015

Kabul ediliş (Accepted): 15.05.2015
} 


\section{Giriş}

Şevketi bostan bitkisi gıda olarak tüketilmesinin yanında tıbbi özellikleri de olan Asteraceae familyasından bir bitkidir. Sarı et al. (2011), ülkemizde Ege, Marmara, Karadeniz, Akdeniz ve ç Anadolu Bölgelerinde yaygın olarak bulunduğunu bildirmektedir. Yakın zamana kadar yabani bir bitki olarak toplanan bitki, Ege Tarımsal Araştırma Enstitüsü tarafından kültüre alınmıştır. Üretiminin yaygınlaşarak fiyatının düşmesi ile, hem lezzetli bir sebze, hem de doğal bir şifa kaynağı olan şevketi bostanın yaygın olarak kullanılan bir ürün haline gelmesi beklenmektedir (Tutar et al., 2013).

Gıda Tarım ve Hayvancılık Bakanlığı tarafından gerçekleştirilen şevketi bostan ile ilgili "Tarımsal Yeniliklerin Yaygınlaştırılması, Bitkisel Üretimi Geliştirme Projesi” 2012 yılında zmir'in Urla, Çeşme, Seferihisar, Kemalpaşa, Menemen ve Aliağa ilçelerinde 55 dekar alanda 32 üretici ile yürütülmüştür. Üreticilerin birçoğu üretimi yaygınlaştırarak sürdürmektedir. Seferihisar ıçe Tarım Müdürlüğü'nden edinilen bilgiye göre Seferihisar'da yalnızca Orhanlı köyünde şevketi bostan üretimi yapılmaktadır.

Kültüre alınarak üretimi yapılan şevketi bostan bitkisi zararlıları ile ilgili olarak ilk kez yapılan bu çalışma ile zarara neden olan türler ortaya konmuştur. Çalışma sırasında belirlenen üreticilerin mevcut uygulamaları ile entomolojik sorunlar saptanarak, elde edilen verilerin ileride yapılacak mücadele programlarının oluşturulmasına yönelik çalışmalara yardımcı olması amaçlanmıştır.

\section{Materyal ve Yöntem}

Çalışmanın ana materyalini 2013-2014 yıllarında zmir ili, Seferihisar ilçesi, Orhanlı köyündeki organik üretimi yapılan şevketi bostan bitkisi ile bu bitkilerdeki böcek türleri oluşturmuştur. Çizelge 1'de görüldüğü gibi çalışmanın yapıldığı Orhanlı köyünde yöreyi temsil edebilecek özellikte 6 farklı örnekleme tarlası seçilmiştir. Örneklemeler, Seferihisar ilçesinde Gıda Tarım ve Hayvancılık Bakanlığı tarafından yürütülen "Tarımsal Yeniliklerin Yaygınlaştırılması, Bitkisel Üretimi Geliştirme Projesi" kapsamında tohumların ücretsiz olarak dağıtıldığı şevketi bostan üretimine başlayan yenilikçi ve güvenilir üreticilere ait 1-1.5 dekar büyüklüğündeki 6 farklı tarlada gerçekleştirilmiştir.

Çizelge 1. Orhanlı köyünde çalışmanın yapıldığı 6 farklı örnekleme tarlaları hakkında bilgiler

\begin{tabular}{|c|c|c|c|}
\hline Tarla & Mevki & Koordinatları & Alan \\
\hline 1 & Orhanlı & 3809'37.0"N 26056'28.6"'E & $1.0 \mathrm{da}$ \\
\hline 2 & Orhanlı & $38^{\circ} 11^{\prime 2} 21.0^{\prime \prime} \mathrm{N} 26^{\circ} 58^{\prime} 42.6$ "'E & $1.5 \mathrm{da}$ \\
\hline 3 & Orhanlı & $38^{\circ} 08^{\prime} 40.0^{\prime \prime} \mathrm{N} 26^{\circ} 55^{\prime} 10.1^{\prime \prime} \mathrm{E}$ & $1.5 \mathrm{da}$ \\
\hline 4 & Orhanlı & $38^{\circ} 08^{\prime} 33.2^{\prime \prime} \mathrm{N} 26^{\circ} 55^{\prime} 22.8^{\prime \prime} \mathrm{E}$ & $1.5 \mathrm{da}$ \\
\hline 5 & Orhanlı & $38^{\circ} 08^{\prime} 45.2^{\prime \prime} \mathrm{N} 26^{\circ} 55^{\prime} 12.2^{\prime \prime} \mathrm{E}$ & $1.0 \mathrm{da}$ \\
\hline 6 & Orhanlı & $38^{\circ} 08^{\prime} 43.0^{\prime \prime} \mathrm{N} 26^{\circ} 55^{\prime} 12.5^{\prime \prime} \mathrm{E}$ & $1.0 \mathrm{da}$ \\
\hline
\end{tabular}

Bu çalışma kapsamında bir yıl süresince, 2013 Ağustos ayında tohumların ekilmesinden, 2014 Ağustosa kadar tohumların olgunlaştığı dönemde şevketi bostan bitkilerinde bulunan zararlılar gözlemlenmiştir.

Doğadan bitkilerin üzerinden toplanan erginlerden, büyükler elle, küçükler ise aspiratör yardımıyla alınıp, etil asetat ile öldürülerek etiket bilgileri de eklendikten sonra teşhise hazır hale getirilmiştir. Ergin öncesi dönemlerden; sabit yaşayanlar bulundukları bitki parçaları ile diğerleri ise kavanoz, kutu gibi araçlar içerisinde sıcaklık, kuraklık gibi koşullardan etkilenmemeleri için gerekli önlemler alınarak ve beslenmeleri de göz önünde tutularak şevketi bostan bitkisi ile birlikte sağlıklı ve canlı olarak kültüre alınacağı yere getirilmişlerdir. Havalandırmayı sağlamak için üzeri tülbentle kaplı havalandırma delikleri bulunan petri kapları içerisinde ya da kavanozlarda kültüre alınan bireylerden ergin çıkışı gözlendiğinde bu tarihler not edilip, teşhise gönderilmek üzere hazırlanmıştır. 
Popülasyon değişiminin izlenmesi çalışmaları, bitkinin ekimiyle birlikte başlamıştır. Belirlenen parseller tarlayı temsil edecek şekilde örnek alabilmek için tarlaya köşegenler doğrultusunda girilerek zikzak oluşturacak şekilde yürünmüş, tarlanın büyüklüğüne göre belirlenen noktalarda tesadüfî olarak, haftada 100 bitkinin üst aksamında zararlı sayımları 3 ay boyunca gerçekleştirilmiştir. Daha sonra iki haftada bir 100 bitkinin üst aksamında zararlı sayımları 3 ay boyunca sürdürülmüştür. Tohum elde edilinceye kadar da ayda bir defa sayımlar gerçekleştirilmeye devam edilmiştir.

Kuruma ve hasar görülen bitkiler ile hasat sırasında toprakaltı kısımlar incelenip zararlı ile bulaşıklık durumu belirlenmiştir. Hasattan sonra tohum almak için ayrılan 10 bitkide zararlı sayımları devam etmiştir. Bu süreçlerde kontrol edilen bitkilerde herhangi bir zararlıya ait bir birey bile bulunsa o bitki, o zararlı için bulaşık kabul edilmiştir. Bulunan zararlılar arasında ergin öncesi dönemler kültüre alınıp ergin çıkışları gözlemlenmiştir.

\section{Araştırma Sonuçları ve Tartışma}

Sayımların yapıldığı tarlalarda Orthoptera (Acrididae), Hemiptera (Aphididae, Aphrophoridae, Pentatomidae, Scutelleridae ve Lygaeidae), Coleoptera (Cetoniidae ve Coccinellidae) ve Diptera (Agromyzidae) takımlarına ait 15 tür tespit edilmiştir (Çizelge 2).

Çalışma sonucunda, zararlı türler arasından en yoğun bulunan ve ileride zarar yapma potansiyellerinin yüksek olduğu düşünülen Chromatomyia horticola (Goureau, 1851), Liriomyza sativae (Blanchard, 1938) (Diptera: Agromyzidae) ve Brachycaudus helichrysi (Kaltenbach,1843) (Hemiptera: Aphididae) türlerinin popülasyon yoğunlukları belirlenmiştir.

Çizelge 2. Şevketi bostan tarlalarında 2013-2014 yıllarında saptanan böcek türleri

\begin{tabular}{|c|c|c|}
\hline Takım & Familya & Tür \\
\hline Orthoptera & Acrididae & $\begin{array}{l}\text { Calliptamus barbarus barbarus (Costa, 1836) } \\
\text { Calliptamus coelesyriensis coelesyriensis (Giglio-Tos, 1893) }\end{array}$ \\
\hline \multirow{7}{*}{ Hemiptera } & Aphididae & Brachycaudus helichrysi (Kaltenbach,1843) \\
\hline & Aphrophoridae & Philaenus spumarius (Linnaeus, 1758) \\
\hline & & Codophila varia (Fabricius, 1787) \\
\hline & Pentatomidae & Dolycoris baccarum (Linnaeus, 1758) \\
\hline & & Carpocoris mediterraneus (Tamanini, 1958) \\
\hline & Scutelleridae & Odontotarsus purpureolineatus (Rossi, 1790) \\
\hline & Lygaeidae & Lygaeus equestris (Linnaues, 1758) \\
\hline \multirow{2}{*}{ Coleoptera } & Cetoniidae & $\begin{array}{l}\text { Tropinota (Epicometis) hirta suturalis (Reitter, 1913) } \\
\text { Tropinota (Tropinota) squalida squalida (Scopoli, 1783) }\end{array}$ \\
\hline & Coccinellidae & $\begin{array}{l}\text { Coccinella septempunctata (Linnaues, 1758)* } \\
\text { Hippodamia variegata }(\text { Goeze, } 1777)^{\star}\end{array}$ \\
\hline Diptera & Agromyzidae & $\begin{array}{l}\text { Chromatomyia horticola (Goureau, 1851) } \\
\text { Liriomyza sativae (Blanchard, 1938) }\end{array}$ \\
\hline
\end{tabular}

* Yararlı türler 
Sayım yapılan tarlalarda 2013 yılında saptanan C. horticola ve L. sativae türlerinin bitkilerde bulunan galerilerinin popülasyon değişimi Şekil 1'de görülmektedir. Tarla 1'de Ekim ayında başlayan artış Kasım ayının ilk haftasına kadar devam etmiş ve daha sonra düşüş periyoduna girerek Aralık ayında sonlanmıştır. Tarla 2'de ise Eylül ayı ile başlayan artış Ekim ayının ortasından itibaren düşüşe geçerek Aralık ayı başlarında sonlanmıştır. Diğer tarlalarda ise Eylül ayında başlayan artışlar dalgalı bir biçimde devam ederek Kasım ayından itibaren düşüşe geçmiştir.

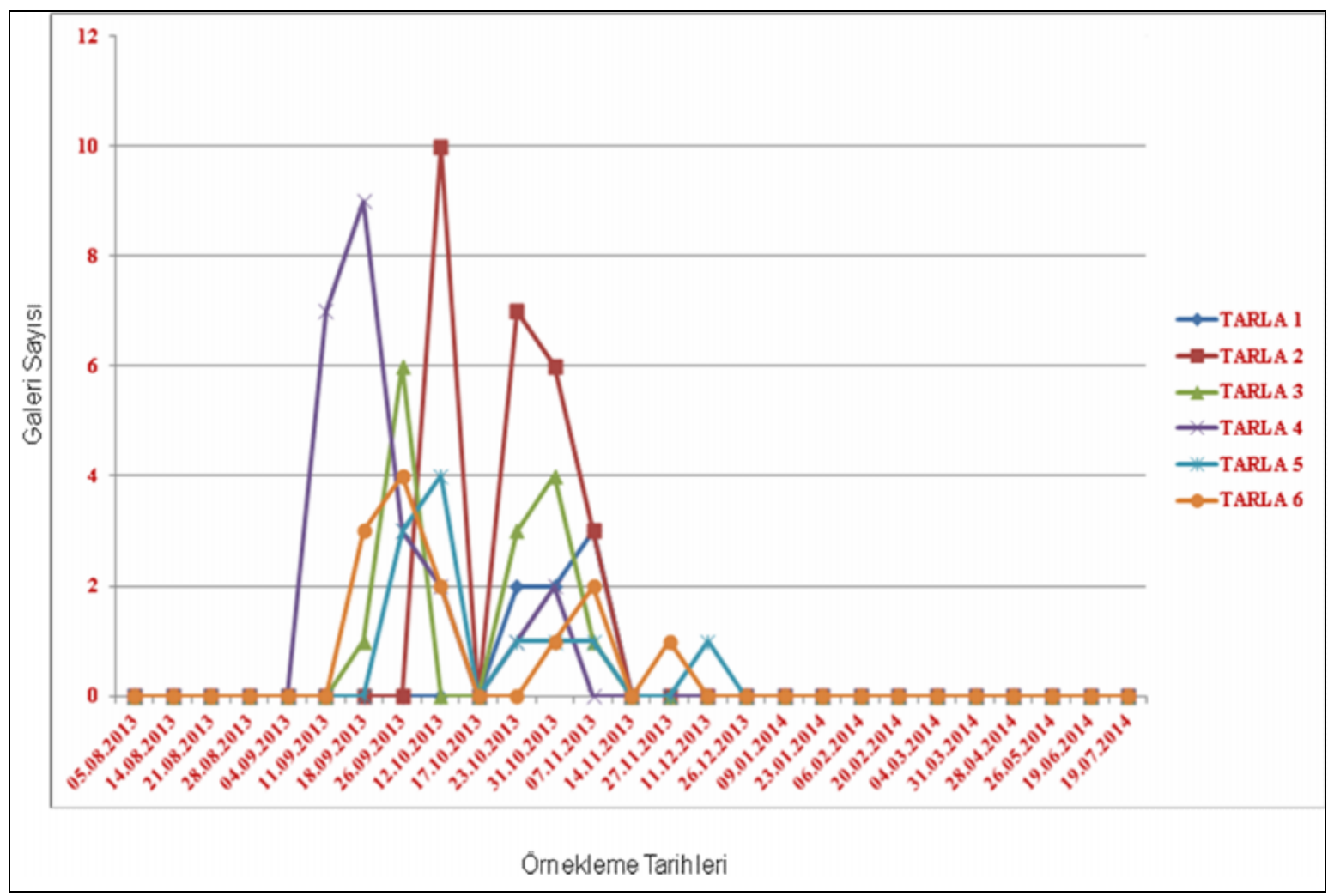

Şekil 1. 2013 yılında çalışmanın yapıldığı tarlalarda görülen Chromatomyia horticola ve Liriomyza sativae türlerinin bitkide bulunduğu galerilerin popülasyon değişimi.

Deneme yürütülen tarlalarda 2013-2014 yıllarında $B$. helichrysi türünün popülasyon değişimi Şekil 2'de görülmektedir. Yapılan gözlemlerde Aralık sonunda tüm tarlalarda artışa geçen popülasyonlar Ocak ayında düşüşe geçmiş ve Mart başı gibi sonlanmıştır.

Chromatomyia horticola ve L. sativae türleri Eylül 2013 tarihinden Aralık 2013'e kadar tarlalarda görülmüştür. Aralık 2013 sonunda görülmeye başlayan B. helichrysi türü Mart 2014'e kadar tarlalarda gözlenmiştir. Ayrıca tarlalarda Aralık 2013 tarihinde görülmeye başlayan Philaenus spumarius (Linnaeus,1758) türü Mart 2014'te artış gösterip Mayıs 2014 sonuna kadar, Haziran 2014'te görülmeye başlanan Codophila varia (Fabricius, 1787), Dolycoris baccarum (Linnaeus, 1758) ve Carpocoris mediterraneus (Tamanini, 1958) türleri temmuz ayı sonuna kadar tarlalarda saptanmıştır. Ancak $P$. spumarius, $C$. varia, $D$. baccarum ve $C$. mediterraneus türlerinin popülasyon oluşturmalarına rağmen gözlemler sırasında şevketi bostan bitkisinde herhangi bir zararlarına rastlanmamıştır. Saptanan zararlı türler içerisinde $C$. horticola, L. sativae, B. helichrysi yoğun olarak bulunmuş olup, zarar açısından ileride üzerinde durulması gereken türler olarak kabul edilmiştir. 


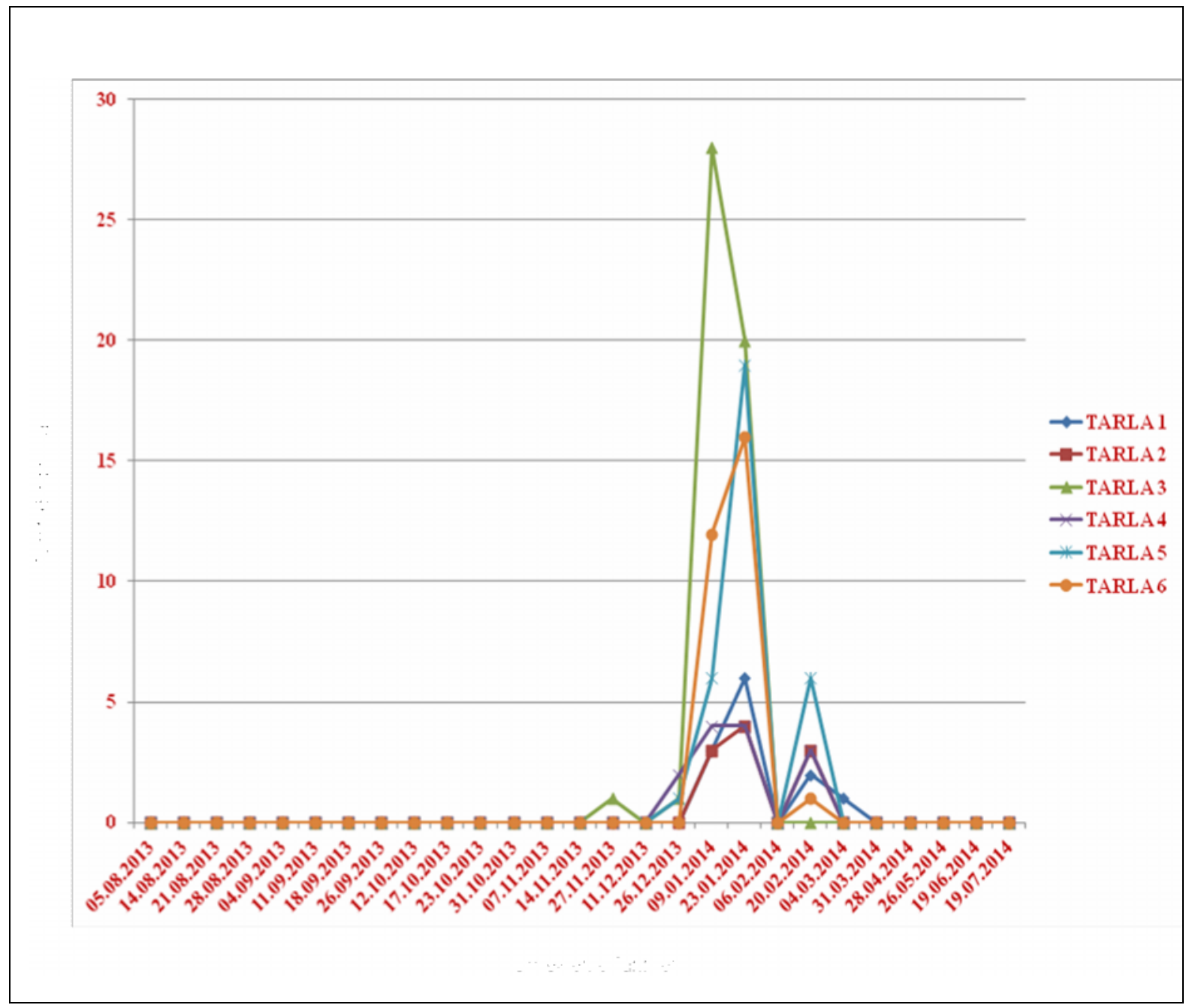

Şekil 2. 2013-2014 yıllarında tarlalarda görülen Brachycaudus helichrysi popülasyon değişimi.

Çalışma sonucunda saptanan yararlı ve zararlı türler dışında tohumların ekiminden kısa bir süre sonra bazı tarlalarda yaban domuzu [(Sus sp. (Linnaues, 1758) (Artiodactyla: Suidae))] zararı ile de karşılaşılmıştır.

Çalışmada yararlı tür olarak predatör böceklerden $C$. septempunctata ve $H$. variegata saptanmıştır. Örnekleme sırasında mumya yaprakbiti bireyleri gözlemlenmiş ancak herhangi bir parazitoit çıkışı görülmemiştir.

Codophila varia, $D$. baccarum ve $C$. mediterraneus türlerinin asıl konukçuları arasında şevketi bostan bitkisi de bulunmaktadır (Awad, 2000). Ayrıca Tropinota (Tropinota) squalida squalida (Scopoli, 1783) ve Tropinota (Epicometis) hirta suturalis (Reitter, 1913) türlerinin konukçuları arasında Asteraceae çiçekleri olduğu bildirilmektedir (Anonymous, 2014a,b). Çalışmada tespit edilen diğer türlerden; $C$. horticola, L. sativae, B. helichrysi, P. spumarius, O. purpureolineatus, L. equestris, C. barbarus barbarus, C. coelesyriensis coelesyriensis'in esas konukçularının arasında şevketi bostan bitkisinin kayıtlı olmadığı belirlenerek, ilk kez şevketi bostan bitkisinde zarar yaptıkları bu çalışma ile ortaya konmuştur. 
Türkiye'de şevketi bostan bitkisi ile ilgili yapılan çalışmalara bakıldığında, zararlılar üzerine yapılmış çalışmaların çok az sayıda olduğu görülmektedir. Kart Gür \& Gür (2010) memeli türler arasında bulunan Spermophilus xanthoprymnus (Bennett, 1835) (Rodentia: Sciuridae)'un konukçuları arasında $S$. hispanicus türünün olduğunu, Akyürek et al. (2012) Brevicoryne brassicae (Linnaeus, 1758) türünün bu bitkinin çiçeği üzerinden elde edildiğini, Bayrak \& Hayat (2012) Acanthiophilus helianthi (Rossi, 1794) (Diptera: Tephritidae)'nin konukçuları arasında $S$. hispanicus türünün bulunduğunu bildirmektedirler.

Dünyada şevketi bostan bitkisi ile yapılan çalışmalara bakıldığında ise, Viggiani (1978) yaptığı çalışmada özellikle zeytin ağacı altında ya da yakınında bulunan Carduus pycnocephalus, Carlina corymbosa ve S. hispanicus gibi yabani bitkilerin Saissetia oleae (Olivier, 1791) (Hemiptera: Coccidae)'nin önemli konukçuları arasında olduğunu bildirmektedir. Knio et al. (2002)'in yaptığı çalışmada ise Acanthiophilus helianthi (Rossi, 1794) (Diptera: Tephritidae)'nin Mayıs-Haziran aylarında $S$. hispanicus üzerinde bulunduğu bildirilmektedir. El Mouden et al. (2006) Fas'ta Testudo graeca graeca (Linnaeus, 1758) (Chelonii: Testudinidae) türünün, Raspudic et al. (2009) Hırvatistan'da Oxythrips bicolor (O. M. Reuter, 1879) (Thysanoptera: Thripidae) türünün, Guesmi et al. (2010) Dysaphis cynarae (Theobald, 1915) (Hemiptera: Aphididae)'nin, Karimpour (2011) Acanthiophilus helianthi (Rossi, 1794) (Diptera: Tephritidae)'nin, Halima (2012) Dysaphis cynarae (Theobald, 1915) (Hemiptera: Aphididae)'nin, Osborne (2015) Apion carduorum (W. Kirby, 1808) (Coleoptera: Apionidae)'un, yaptıkları çalışmalarda konukçuları arasında $S$. hispanicus türünün olduğunu bildirmektedirler.

Sonuç olarak yakın zamanda kültüre alınarak üretimi yapılan şevketi bostan bitkisinde ilk defa yapılan bu çalışma ile zararlı ve yararlı türler tespit edilerek, C. horticola, L. sativae, B. helichrysi nin zarar açısından ileride üzerinde durulması gereken türler olduğu kanısına varılmıştır.

\section{Teşekkür}

Zararlı türlerin teşhisinde yardımcı olan Prof. Dr. Hasan Sungur C VELEK (Muğla Sıtkı Koçman Üniversitesi, Fen Fakültesi, Biyoloji Bölümü, Kötekli, Muğla), Dr. Işıl ÖZDEM R (Tarımsal Fauna ve Mikroflora Bölümü, Zirai Mücadele Merkez Araştırma Enstitüsü Müdürlüğü, Ankara), Dr. Mustafa ÜNAL (Abant zzet Baysal Üniversitesi, Fen-Edebiyat Fakültesi, Biyoloji Bölümü, Bolu), Yrd. Doç. Dr. Yakup ŞENYÜZ (Dumlupınar Üniversitesi Merkez Kampüsü, Fen-Edebiyat Fakültesi, Biyoloji Bölümü, Kütahya), Prof. Dr. Ünal ZEYBEKOĞLU (Ondokuz Mayıs Üniversitesi, Fen ve Edebiyat Fakültesi, Biyoloji Bölümü, Samsun), Doç. Dr. Meral FENT (Trakya Üniversitesi, Fen Fakültesi, Biyoloji Bölümü, Zooloji Anabilim Dalı, Edirne)'e teşekkürü bir borç biliriz.

\section{Yararlanılan Kaynaklar}

Anonymous, 2014a. The Scarabs of the Levant: Syria, Lebanon, Jordan, Palestine, Israel and Sinai, "Scarabaeidae Cetoniinae", Tropinota (Epicometis) hirta ssp. suturalis Reitter, 1913. (Web sayfası: http://www.glaphyridae.com/Cetoniinae/Tr_hirta.html), (Erişim tarihi: Eylül 2014).

Anonymous, 2014b. The Scarabs of the Levant: Syria, Lebanon, Jordan, Palestine, Israel and Sinai, "Scarabaeidae Cetoniinae", Tropinota (Tropinota) squalida ssp. pilosa Brulle, 1832. (Web sayfası: http://www.glaphyridae.com/Cetoniinae/Tr_squalida.html), (Erişim tarihi: Eylül 2014).

Akyürek, B., Ü. Zeybekoğlu \& G. Görür, 2012. Ondokuz Mayıs Üniversitesi Kurupelit yerleşkesi (Samsun)'nin yaprakbiti (Hemiptera: Aphididae) türleri ve konukçu bitkileri. Türk. Entomol. Bült., 2(2): 91-108.

Awad, T. I., 2000. Türkiye Carpocorini (Heteroptera: Pentatomidae: Pentatominae) Türleri Üzerinde Sistemastik ve Faunistik Araştırmalar, Ege Üniversitesi Fen Bilimleri Enstitüsü, Doktora Tezi, zmir, 172s. 
Bayrak, N. \& R. Hayat, 2012. Türkiye'nin Tephritidae (Diptera) türleri. Türk Bilimsel Derlemeler Dergisi, 5(2): 49-55.

El Mouden, E. H., T. Slimani, K. Ben Kaddour, F. Lagarde, A. Ouhammou \& X. Bonnet, 2006. Testudo graeca graeca feeding ecology in an arid and overgrazed zone in Morocco. Journal of Arid Environments, 64: 422-435.

Guesmi, J., M. Ben Halima-Kamel \& B. Almohandes-Dridi, 2010. Identification and population evolution of aphids infesting artichoke in Tunisia. Tunisian Journal of Plant Protection, 5: 83-89.

Halima, M. K. B., 2012. Aphid fauna (Hemiptera: Aphididae) and their host association of chott mariem, coastal area of Tunisia. Annals of Biological Research, 3(2): 746-754.

Karimpour, Y., 2011. Fruit flies (Dip.: Tephritidae) reared from capitula of Asteraceae in the Urmia region, Iran. Journal of Entomological Society of Iran, 30(2): 53-66.

Kart Gür, M. \& H. Gür, 2010. Mammalian species, American Society of Mammalogists, 42(864): 183-194.

Knio, K. M., S. H. Kalash \& I. M. White, 2002. Flowerhead-infesting fruit flies (Diptera: Tephritidae) on thistles (Asteraceae), in Lebanon. Journal of Natural History, 36: 617-629.

Osborne, P. J., 2015. An insect fauna from the Roman site at Alcester, Warwickshire. Society for the Promotion of Roman Studies, 105: 156-165.

Raspudic, E., M. Ivezic, M. Brmez \& S. Trdan, 2009. Distribution of Thysanoptera species and their host plants in Croatia. Acta Agriculturae Slovenica, 93(3): 275-283.

Sarı, A., M. Tutar, A. Bilgiç, K. Başer, G. Özek \& M. Koşar, 2011. Şevketi bostan (Scolymus hispanicus L.) bitkisini kültüre alma ve seleksiyon ıslahı. Anadolu, J. of AARI, 21(2): 1-10.

Tutar, M., A. Sarı \& A. Bilgiç, 2013. Şevketi bostan yetiştiriciliği, Çiftçi Mektubu, Ege Tarımsal Araştırma Enstitüsü, Menemen- zmir.

Viggiani, G., 1978. Current ctate of biological control of olive scales. Boll. Lab. Ent. Agr., 35: 30-38. 